\title{
Developmental Dysplasia of the Hip
}

\author{
Priyanka Kumari* and Manisha Rani \\ Assistant professor, MM Institute of Nursing, India
}

Submission: January 23, 2018; Published: February 21, 2018

*Corresponding author: Priyanka Kumari, Assistant Professor, M.M Institute of Nursing, Maharishi Markenehwer University, MullAna Ambala, Haryana, India, Email: priyankakumari@mmumullana.org

\begin{abstract}
Developmental dysplasia of hip (DDH) is rare condition occurs in growing hip with structural abnormalities. Early finding and management provides the best possible result. Hip dysplasia into teens and later life may result in irregular gait, reduced the strength and generate many hip and knee disease. Developmental dysplasia should be treated soon after death. Different diagnostics test for Developmental dysplasia of hip were invented to treat with this condition. Radiography, ultrasonography and magnetic resonance imaging help to identify the dislocation. Surgical treatment usually consists of open reduction and hip reconstruction surgery. Review contains the current practicing for identifying the DDH and its treatment.
\end{abstract}

Keywords: Dysplasia; Children; Hip; Developmental dysplasia of the hip

\section{Introduction}

Developmental dysplasia of the hip (DDH) describes entire range of deformities involving the growing hip including acetabulum, and dysplasia of the femoral head. During birth some children have a normal femoro acetabular relationship but later stage it generate dysplastic hip [1]. Hip is unbalanced when the junction between the acetabulum and femoral get unstable and femoral head move up to some limit or enable to move [2]. Inadequate contact between the acetabulum and articular surface of femoral head is called Subluxation of hip. Dislocation leads to various malformation like multiplex congentia, spinabifida, diastropic dwarfism etc. Some irregular muscle tension leads to inheritance of dysplasia of the hip [3]. The classification developmental of dysplasia of the hip according to ultrasound system is termed Graf method which combines both alpha and beta angels in infant.

\section{Etiology}

DDH etiology depends upon multiple factors. Various factors are responsible for inheritance of DDH is neuropediatric disorders with an abnormal muscle tension, including myelomeningocele, cerebral palsy and arthrogryposis and hereditary ligament laxity [4]. Other than this breech presentation \& postnatal positioning may also cause DDH in few cases. Female new-borns respond to relaxing hormones releasing from maternal placenta so they are more likely to develop hip displacement disorders [5-9]. Identical twins are more prone to development of hip dysplasia than fraternal twins. Presence of twins or multiple fetus causes intrauterine crowding which may disturb hip development during fetal life. Methods of baby wrapping in extended position may lead to DDH more easily than the babies wrapped in abducted positions [10-13].

\section{Diagnosis}

All new born should undergo a careful clinical examination especially those who are at risk of DDH. By using Ortolani test and Barlow maneuver routine screening of each hip should be done separately [14]. For performing physical examination, a smooth, warm, comfortable surface is required in a calm environment and the child should be completely relaxed [15-18]. In new born infants, Hip instability was reported by Roserin 1879. After that, in 1910, a clinical test for hip instability was described by Le Damany and Saiget and this was emphasized by Ortolani in 1937 followed by the further tests to incite dislocation or subluxation was developed by Palmen and Barlow in 1961 and 1962.

\section{Ortolani Test}

In this test, place the baby in supine position with flexed hips at 90 degree. Index and long fingers of the examiner are kept laterally on the greater trochanter of the child and position the thumb medially near the groin crease [19]. Stabilize the child's pelvis by holding the contra lateral hip andusing opposite hand gently abducts the hip being tested by exerting an upward force simultaneously through the greater trochanter on lateral side. The perception of a palpable clunk indicates positive Ortolani test and along with this also represents the reduction of a dislocated hip into the acetabulum [20]. 


\section{Barlow's, Maneuver}

For performing this maneuver, stabilize the pelvis and position the patient similar to the Ortolani test position i.e. supine with leg flexed at 90 degrees. The Barlow's test identifies posterior sublimations or dislocation. It is performed by applying a gentle downward force in the longitudinal axis of the femur but after three to six months of age, contractures of soft tissue occur that limit the motion of the hip even if it is dislocated (Figure 1). In case of an older child examination also includes careful assessment, which consists of keen evaluation of extremities for presence of asymmetric skin folds or discrepancy in length of both legs especially in case of unilateral hip dislocation [21].

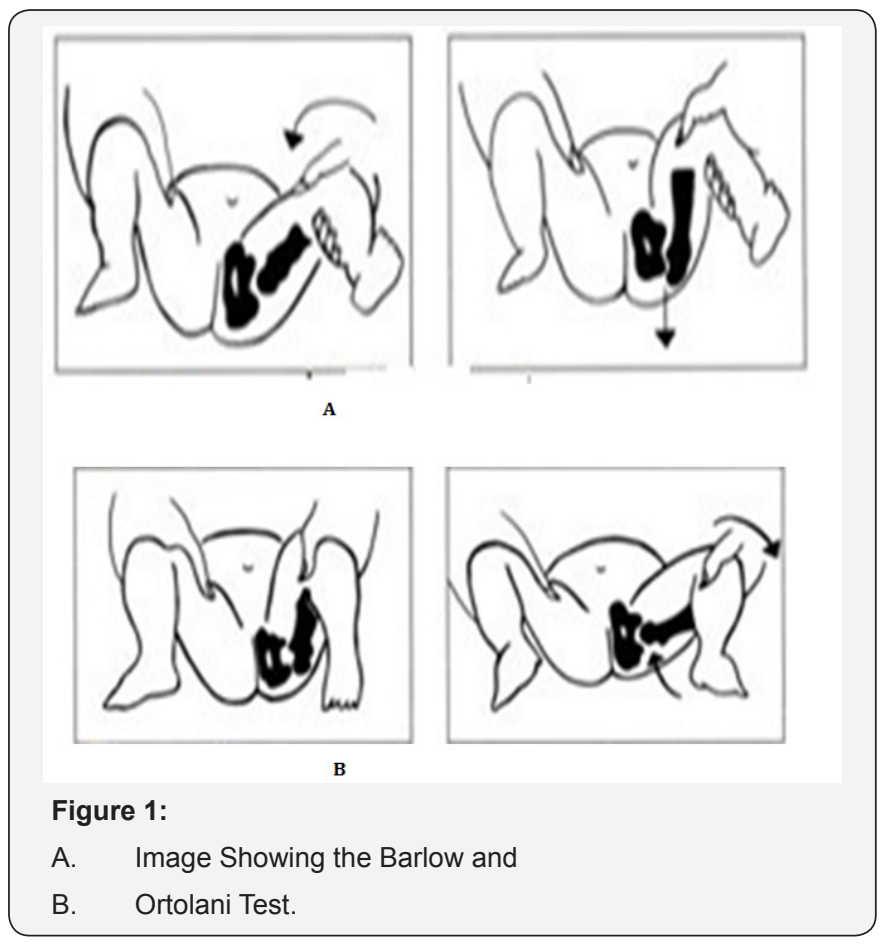

\section{Galeazzi Sign}

Also known as Allis sign. A positive Galeazzi sign is another important indicator of hip dislocation. It is prompted by lying down the child in supine position followed by flexing both the knees so that feet touches the ground and the ankles touches the buttocks [22]. If an inequality in the height of the knees appeared, it indicates a positive sign (Figure 2). In neglected cases, DDH may be diagnosed when children attain walking age with a sagging on the affected side.

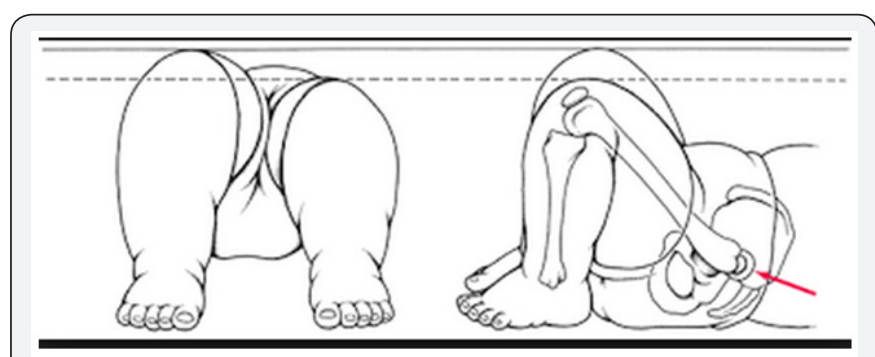

Figure 2: Showing the Galeazzi test.

\section{Plain Radiographs and Ultrasonography}

During the neonatal period, baby is having largely cartilaginous femoral head and acetabulum, so plain radiographs are not much useful in diagnosis. In infants younger than 6 months of age, ultrasonography has much value to assess DDH. Especially in starting 6 weeks of life, false diagnosis of DDH may occur because this assessment is totally dependent upon observer evaluation and as a result of false positive results infant may undergo needless action [23]. Routine ultrasonography is recommended in many western countries. At the age of 3-6 months dislocation of hip will be apparent on $\mathrm{x}$ - rays, if evaluator is aware about the immature pelvis landmarks (Figure 3).

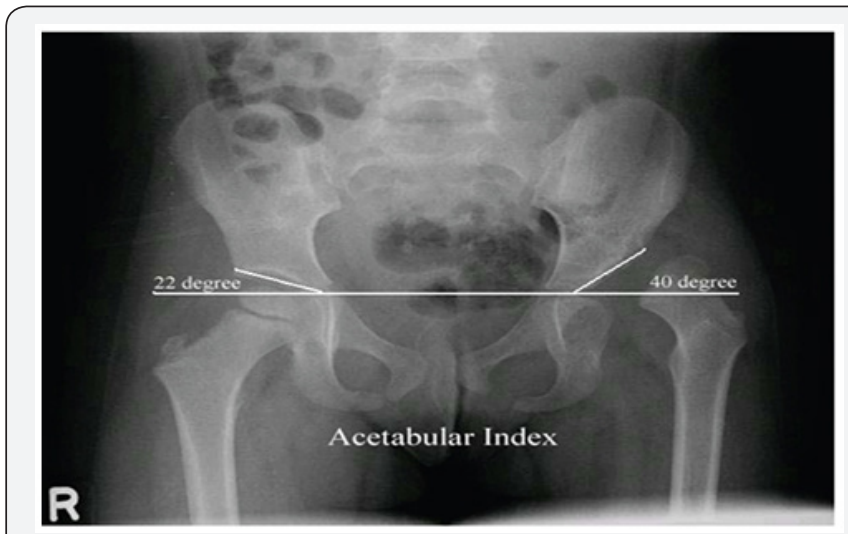

Figure 3: Pelvis X-Ray (AP view) showing left sided dysplastic hip with femur head lying in the upper outer quadrant.

Management of developmental dysplasia of the Hip

Management of DDH depends on the age, the best results can be gained if treatment initiated at early age. The main aim of the treatment is to attain fixing of femoral head inside acetabulum.

\section{Non-Surgical Treatment of Ddh}

In last era DDH treatment of was developed, it was first anticipated by Lorenz, in this he focused on closed reduction with application of plaster cast in stable maximal abduction. Previously, it was very tough to diagnose babies until their walking starts. After that in 1900's introduction of radiograph occur

In babies, at age of 12 months diagnosis of dislocation was firstly introduced by Ortolani, with help of a clinical test i.e. known as Ortolani manoeuvre [24]. He also gave an abduction brace. Followed by this, a harness and stirrups system was came in practice which is of huge use in today's world known as Pavlik harness. It is the most likely used method of orthosis of choice.

The Pavlik harness device made up of 2 shoulder straps crossing over the back and secured to a wide thoracic belt on the anterior side (Figure 4). Along with hips, holed at $90^{\circ}$ flexed position and the legs are fixed in drape shaving two ties. The anterior strap used to keep the hips in flexion with some extension and posterior strap are beneficial to stop the lower limb breaking the midline to avoid adduction. It is suggested by the Grill et al that position given in pavlik harness is like to the 
position of babies naturally carried on a mothers' back position involving thighs in flexed attitude.

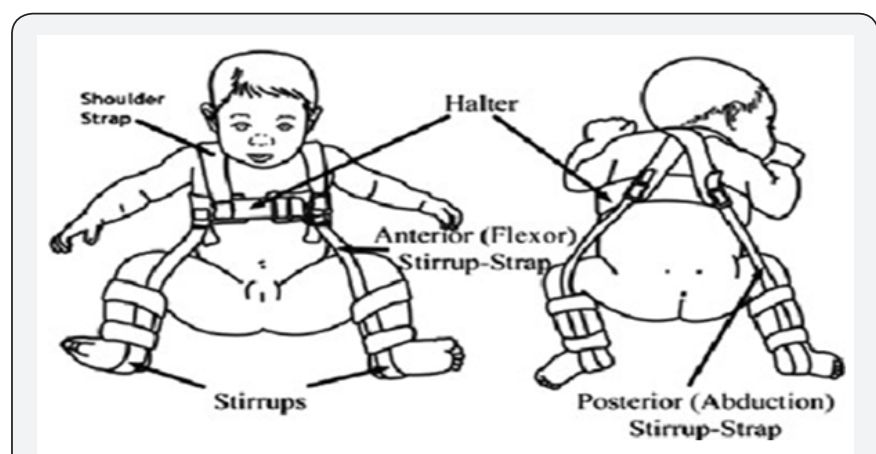

Figure 4: Pavlik harness device.

The key aim of pavlik harness focus on regain of normal improvement by atraumatic, repositioning and conservation of the hip joint functions. Primarily, skilful reduction of the hip depends on passive abduction and flexion [25]. In few cases which are having muscle imbalance like myelomening ocele, arthrogryposis (major stiffness), Ehlers-Danlos syndrome i.e. ligamentous laxity; Pavlik harness is contraindicated 14.

\section{Pavlik Harness Treatment Regimes}

Different duration was suggested by various research studies. A study conducted by Erlacher recommended his patients 6 month time period to wear the pavlik harness, other than this Whilst Hirsch et al suggested duration of 3 months. Mubarak et al. [21] added his concept and advised to wear harness according to age i.e. less than 3 month baby should use it for 3 months and proposed approximately double time period for 4 month and older baby. All of these suggested about the follow up care including harness adjustment and ultrasonography on weekly basis. It is believed that new-born with true dislocation regain hip stability in time period of three weeks.

\section{Surgical Treatment of Ddh}

Surgical regimes are taken when failure of closed reduction or pavlik harness occur. This treatment of DDH focuses on open reduction techniques along with osteotomy of femoral and pelvic region [26]. If femoral neck have excessive anteversion or valgus deformity than femoral osteotomies remains beneficial. Various type of osteotomies of pelvic region are available like Pemberton pericapsular osteotomy, that likely to be chosen in scenario where the acetabular index is more than $40^{\circ}$ and Salter innominate osteotomy which is an open wedge osteotomy that spreads the acetabulum around a fixed axis so that the femoral head both superiorly and anteriorly covered by the acetabular roof, Various complications of DDH surgical regimes occur that are: damage of sciatic nerve, AVN, migration and breakage of K-wire, epiphyseal centre damage, and fracture of femoral region $[27,28]$.

\section{Conclusion}

Developmental dysplasias of the hip (DDH) describe entire range of deformities involving the growing hip including acetabulum, and dysplasia of the femoral head. Screening programmes for DDH still vary worldwide and more largescale, longitudinal studies are needed to allow standardisation of policy across regions. Ultrasound imaging allows morbidity can be reduced by doing appropriate management of DDH. The Pavlik stimulate progress in the fruitful treatment of DDH with a decline in developmental disturbance and short duration complications. Follow up care including harness adjustment and ultrasonography is required on weekly basis. Harness failure can cause devastating AVN and femoral as well as acetabular developmental disturbance. When harness treatment got failed then surgical management is one and only last option for DDH patients. Combination of both i.e. open reduction and femoral/ pelvic osteotomy have good prognosis.

\section{References}

1. Ponseti IV (1978) Morphology of the acetabulum in congenital dislocation of the hip. Gross, histological and roentgenographic studies. J Bone Joint Surg Am 60(5): 586-599.

2. Aronsson DD, Goldberg MJ, Kling TF (1994) Developmental dysplasia of the hip. Pediatrics 94: 201-208.

3. American Academy of Pediatrics (2000) Committee on Quality Improvement, Subcommittee on Developmental Dysplasia of the Hip: Clinical practice guideline: Early detection of developmental dysplasia of the hip. Pediatrics 105: 896-905.

4. LeBel ME, Gallien R (2005) The surgical treatment of teratologic dislocation of the hip. J Pediatr Orthop B 14(5): 331-336.

5. Wynne-Davies R (1970) Acetabular dysplasia and familial joint laxity: Two etiological factors in congenital dislocation of the hip. A review of 589 patients and their families. J Bone Joint Surg Br 52(4): 704-716.

6. Pavlik A (1992) The functional method of treatment using a harness with stirrups as the primary methods of conservative therapy for infants with congenital dislocation of the hip 1957. Clin Orthop Relat Res 281: 4-10.

7. Yamamuro T, Ishida K (1984) Recent advances in the prevention, early diagnosis, and treatment of congenital dislocation of the hip in Japan. Clin Orthop Relat Res 184: 34-40.

8. Kutlu A, Memik R, Mutlu M, Kutlu R, Arslan A (1992) Congenital dislocation of the hip and its relation to swaddling used in Turkey. J Pediatr Orthop 12(5): 598-602.

9. Dezateux C, Rosendahl K (2007) Developmental dysplasia of the hip. Lancet 369: 1541-1552.

10. Barlow TG (1962) Early diagnosis and treatment of dislocation of the hip. J Bone Joint Surg Br 44: 292-301.

11. Harding MG, Harcke HT, Bowen JR, Guille JT, Glutting J, et al. (1997) Management of dislocated hips with Pavlik harness treatment and ultrasound monitoring. J Pediatr Orthop 17(2): 189-198.

12. Godward S, Dezateux C (1998) Surgery for congenital dislocation of the hip in the UK as a measure of outcome screening. MRC Working Party on Congenital Dislocation of the Hip. Lancet 351(9110): 1149-1152.

13. Maxwell SL, Ruiz AL, Lappin KJ (2002) Clinical screening for developmental dysplasia of the hip in Northern Ireland. BMJ 324: 1031-1033. 
14. Weinstein SL, Mubarak SJ, Wenger DR (2004) Developmental hip dysplasia and dislocation: Part II. Instr Course Lect 53: 531-542.

15. Fried A, Seelenfreund M (1969) The treatment of congenital dislocation of the hip by the Pavlik strap brace. Bull Hosp Joint Dis 30(2): 153-163.

16. Anonymous, Pavlik Harness (2016)

17. Grill F, Bensahel H, Canadell J, Dungl P, Matasovic T, et al. (1988) The Pavlik harness in the treatment of congenital dislocating hip: report on a multicenter study of the European Paediatric Orthopaedic Society. J Pediatr Orthop 8(1): 1-8.

18. Herring JA (2002) Developmental Dysplasia of the hip. In: Herring JA. Tachdijan's paediatrics orthopaedics. ( $3^{\text {rd }}$ edn) W.B. Saunders, Philadelphia, USA, pp. 513-654.

19. Ramsey PL, Lasser S, MacEwen GD (1976) Congenital dislocation of the hip. Use of the Pavlik harness in the child during the first six months of life. J Bone Joint Surg Am 58(7): 1000-1004.

20. Hirsch PJ, Hirsch SA (1976) The Pavlik Harness for hip dysplasia: A safe and rapid means of treatment. Orthop Rev 5: 81-83.

21. Mubarak S, Garfin S, Vance R, McKinnon B, Sutherland D (1981) Pitfalls in the use of the Pavlik harness for treatment of congenital dysplasia, subluxation, and dislocation of the hip. J Bone Joint Surg Am 63(8): 1239-1248.

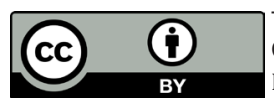

This work is licensed under Creative Commons Attribution 4.0 License

DOI: 10.19080/OROAJ.2018.10.555794
22. Ezirmik N, Yildiz K (2012) Advantages of single-stage surgical treatment with salter innominate osteotomy and Pemberton pericapsular osteotomy for developmental dysplasia of both hips. J Int Med Res 40(2): 748-755.

23. Cui S, Yu F, Li Q Xu W, Xiao S, et al. (2004) Treatment of developmental dislocation of the hip with improved Pemberton method. Zhongguo Xiufu Chongjian Waike Za zhi 18(5): 386-388.

24. Rab GT (1981) Containment of the hip: a theoretical comparison of osteotomies. ClinOrthopRelat Res 154: 191-196.

25. Bursali A, Tonbul M (2008) How are outcomes affected by combining the Pemberton and Salter osteotomies? ClinOrthopRelat Res 466(4): 837-846.

26. Salter RB, Dubos JP (1974) The first fifteen year's personal experience with innominate osteotomy in the treatment of congenital dislocation and subluxation of the hip. Clin Orthop Relat Res 98: 72-103.

27. Salter RB (1961) Innominate osteotomy in the treatment of congenital hip dislocation and subluxation of the hip. J Bone Joint Surg (Br) 43: 518-539.

28. Ezirmik N, Yildiz K (2012) Advantages of single-stage surgical treatment with salter innominate osteotomy and Pemberton pericapsular osteotomy for developmental dysplasia of both hips. J Int Med Res 40(2): 748-755.

\section{Your next submission with Juniper Publishers will reach you the below assets}

- Quality Editorial service

- Swift Peer Review

- Reprints availability

- E-prints Service

- Manuscript Podcast for convenient understanding

- Global attainment for your research

- Manuscript accessibility in different formats

( Pdf, E-pub, Full Text, Audio)

- Unceasing customer service

Track the below URL for one-step submission https://juniperpublishers.com/online-submission.php 